\title{
Population density of Plutella xylostella (Lepidoptera: Plutellidae) and its parasitoid Cotesia plutellae (Hymenoptera: Braconidae) on two varieties of cabbage in an urban environment
}

\author{
Muhammad Haseeb, Youichi Kobori, Hiroshi Amano* and Hisashi Nemoto ${ }^{1}$ \\ Laboratory of Applied Entomology and Zoology, Faculty of Horticulture, Chiba University, Matsudo, Chiba 271-8510, Japan \\ ${ }^{1}$ Saitama Agriculture and Forestry Research Center, Kuki, Saitama 346-0037, Japan
}

(Received 12 July 2000; Accepted 26 March 2001)

\begin{abstract}
Population density of Plutella xylostella on two cabbage varieties (Kinkei 201 and Shinsei) in an urban environment created different pest loads. A maximum larval density of 9.3 larvae per plant was recorded in Kinkei 201 field. In contrast, the corresponding value was 6.3 larvae per plant in Shinsei field. Shinsei cabbage showed lower larval density of pest but higher parasitism by Cotesia plutellae. Four major parasitoids and two hyperparasitoids were collected and identified during the two year period. No egg parasitoids of the DBM were observed. Comparison of C. plutellae parasitism rates between the two varieties in the field showed a higher parasitism rate on Shinsei cabbage. Parasitoid density peaked on July 13 (4.1 cocoons/plant) in Shinsei and on June 27 (2.3 cocoons/plant) in Kinkei 201. Parasitism of host larvae by $C$. plutellae was high on Shinsei cabbage in both years and ranged from 40 to $83.3 \%$. Pest density, parasitism rates and rain impact on Kinkei 201 and Shinsei are discussed.
\end{abstract}

Key words: Plutella xylostella, cabbage, population density, Cotesia plutellae, parasitism

\section{INTRODUCTION}

The diamondback moth (DBM), Plutella $x y$ lostella (Linnaeus), is a cosmopolitan herbivore that feeds exclusively on crucifers (Yaseen, 1978; Talekar and Shelton, 1993; Idris and Grafius, 1996). Population density of the DBM has been studied in various agroecosystems and is well documented on a number of crucifer plants (Iga, 1985; Muckenfuss and Shepard, 1994). Seasonal factors and beneficials play an important role in the growth and development of individual insects as well as the population. Life table and population studies showed that rainfall, temperature, natural enemies and host plants influenced the survival and reproduction of the DBM (Wakisaka et al., 1991; Nemoto et al., 1992; Talekar and Yang, 1993; Noda et al., 1996). Annamalai et al. (1988) recorded 33.1 to $62 \%$ mortality of first stadium pest larvae in cabbage fields due to rainfall and some unknown factors.

The "natural enemies" hypothesis suggested that parasitoids and predators are more effective in complex environments (Sheehan, 1986). Moreover, parasitoids can profoundly influence the popula- tions of their hosts (Haseeb et al., 2000a, b) and are key components of terrestrial ecosystems. Use of parasitoids is one of the most effective and suitable methods for controlling resistant races of pests as observed in the DBM (Hirashima et al., 1989; Talekar and Yang, 1990). Among these parasitoids, Cotesia plutellae (Kurdjumov) (=Apanteles plutellae Kurdjumov) is a primary solitary endoparasitoid of DBM larvae (Okada, 1989; Back and Tabashnik, 1990; Noda et al., 1996; Haseeb and Amano, 2001) and has been reported as an impressive suppressing agent of its population (Lim, 1986; Talekar and Yang, 1993; Mitchell et al., 1999).

Cabbage is an important crucifer vegetable crop grown throughout Japan. The relationship between plant density and arthropod density in cabbage fields and the effect of plant density on the survival of cabbage pests has recently been described in detail (Yamamura, 1999; Yamamura and Yano, 1999). Among other pests, the DBM is considered a serious pest of cabbage in the spring. Various varieties are cultivated throughout the country during this season. Among these varieties, Kinkei 201 and Shinsei are grown for fresh and processed use, re-

* To whom correspondence should be addressed at: E-mail: amano@midori.h.chiba-u.ac.jp 
spectively.

Despite the wealth of knowledge and improved technology which have contributed to the control of the DBM, we are still only just beginning to tackle the major problems of insect resistance and pest resurgence in the DBM, problems which thwart our efforts to control it chemically (Hama, 1990; Adachi and Futai, 1992; Nemoto, 1993). Alternative control measures, which are not only effective but feasible at local farm levels, are urgently needed to solve this problem. It is likely that control measures based on the philosophy of integrated pest management (IPM) will prove useful for DBM management. In this paper we report and discuss: population density of the DBM, occurrence of its parasitoids, host parasitism rates by $C$. plutellae and the potential for use of $C$. plutellae in controlling the pest in the field on two varieties of cabbage, Kinkei 201 and Shinsei.

\section{MATERIALS AND METHODS}

Experimental site. The present study was carried out in the field at the Matsudo campus of Chiba University (Chiba Pref.). The altitude of the campus is about $26 \mathrm{~m}$ above sea level (N 35 $47^{\prime}$, W $139^{\circ} 54^{\prime}$ ). Matsudo campus is situated in the middle of an urban environment. The vegetation at the campus is extremely heterogeneous and disturbed. It is mainly composed of natural and exotic ornamentals, vegetables and fruit-bearing plant species. Almost $50 \%$ of the campus area (14.8 ha) is dominated by various forest tree species. The cabbage fields are located in an area that is surrounded by forest trees on three sides and greenhouses where vegetables (non-crucifers) had previously been grown on the remaining side.

Study fields. Cabbage seeds of two varieties, 'Kinkei 201' (Sakata Seed Co. Inc., Japan) and 'Shinsei' (Tohoku Seed Co. Ltd., Japan) were sown on March 19, 1998 in commercial nursery soil. Two fields of equal size were plowed for cultivation. In one field 70 plants of Kinkei 201 and in the other 70 plants of Shinsei were transplanted on May 8, 1998. Both fields were experimental fields at the campus and were managed using typical agronomic practices except that no pesticide was applied after transplanting.

For the repetition of the study on host parasitism rates of $C$. plutellae, cabbage seeds were sown on
April 7, 1999. Seedlings were transplanted on June 2,1999 . The locations of the fields were reversed. During this season about 60 plants of each variety were cultivated by using similar cultivation practices to those used in 1998. Fields were irrigated through a tubal system and not through sprinklers. Plants that died due to damage by stem and rootcutting ants were replaced by nursery plants.

DBM density on Kinkei 201 and Shinsei. Sampling for population density of various immature stages of the DBM was carried out weekly. Population censuses for eggs, larvae I (1st and 2nd instars), larvae II (3rd and 4th instars) and pupae (prepupae inclusive) were recorded. Sampling was started 2 weeks after transplanting of cabbage and carried out for 10 weeks. A single cabbage plant was used as the basic sampling unit. Twenty plants were sampled weekly from each field (Kinkei 201 and Shinsei). Other lepidopterous larvae observed on plants were removed to provide more space for the DBM larvae to grow. In the case of heavy rain on the scheduled sampling date, sampling was done the next day.

Parasitoid occurrence. DBM eggs, larvae (3rd and 4th instars), prepupae and pupae collected from each field were brought into the laboratory and reared. In the laboratory, eggs, prepupae and pupae were individually kept in Petri dishes (9.50 $\mathrm{cm}$ in diameter), however, larvae were reared on cabbage plants in plastic cages $(34 \mathrm{~L} \times 34 \mathrm{~W} \times 25 \mathrm{H}$ $\mathrm{cm}$, external dimensions). The laboratory temperature was kept at $25 \pm 1^{\circ} \mathrm{C}$ under a photophase of 16L8D. Emerged host pupae and parasitoid cocoons were separated and further reared for adult emergence. The emerged parasitoid wasps were preserved in glass vials containing $75 \%$ alcohol and classified.

Host parasitism rates of $C$. plutellae on Kinkei 201 and Shinsei. The major larval parasitoid $C$. plutellae was recorded on both cabbage varieties. C. plutellae is a larval parasitoid of the DBM but its parasitism in the field could be confirmed in the cocoon stage. The parasitoid was sampled during two cropping seasons (springs of 1998 and 1999) by counting the number of parasitoid cocoons and DBM pupae on 20 cabbage plants at each sampling date in Kinkei 201 and Shinsei fields. By using the host and parasitoid numbers, percentage parasitism prevailing under field conditions was determined.

Statistical analyses. The data of population den- 
sity of P. xylostella and C. plutellae was plotted by averaging the numbers of host and parasitoid per 20 plants sampled in each field. Percentage parasitism was calculated by using the formula:

$$
\begin{aligned}
\% \text { Parasitism }= & \text { No. of } C \text {. plutellae cocoons } \\
& / \text { (No. of } C \text {. plutellae cocoons } \\
& + \text { P. xylostella } \text { pupae }) \times 100 .
\end{aligned}
$$

The relationship of parasitism and host density on Kinkei 201 and Shinsei was investigated using linear regression lines. ANCOVA was carried out and differences between the two varieties were separated by the Fishers' PLSD test (StatView, 1998).

\section{RESULTS}

\section{DBM density on Kinkei 201 and Shinsei}

The density of immature stages of the DBM in Kinkei 201 and Shinsei fields for 10 weeks showed different trends (Fig. 1A and B). In Kinkei 201, the population density of eggs showed roughly three peaks. Egg peak densities per plant were recorded on June 7 (16.2 eggs), June 27 (12.6 eggs) and July 18 (10.3 eggs). Larvae I density was maximum on June 21 (6.4 larvae/plant) and minimum on July 18 (1.6 larvae/plant). However, larvae II density was highest on July 4 (5.5 larvae/plant) and lowest on May 23 (0.1 larva/plant). Pupal density was highest on June 27 (4.5 pupae/plant), whereas no pupae were observed on May 23. The egg density showed that the DBM has 2-3 generations on Kinkei 201 cabbage (Fig. 1A).

In Shinsei field, the mean DBM egg density was highest (17.7 eggs/plant) on June 13. Similar values of 7.3 eggs/plant and 7.81 eggs/plant on June 27 and July 4 were recorded respectively. Larvae I density per plant was highest (2.7 larvae) on June 13 and zero on July 25 . On the other hand, larvae II density was highest (3.1 larvae) on July 4 and lowest ( 0.1 larva) on July 25 . Pupal density was low and was recorded as 0 to 1.3 pupae/plant on various sampling dates. The egg density showed that the DBM also has 2-3 generations on Shinsei cabbage (Fig. 1B).

Comparing the population density of various stages of the DBM between these two varieties, it is apparent that the pest has a heavy load of various stages on Kinkei 201. Moreover, population trends of larvae I (1st and 2nd instars) showed somewhat suppressed growth trends throughout the sampling

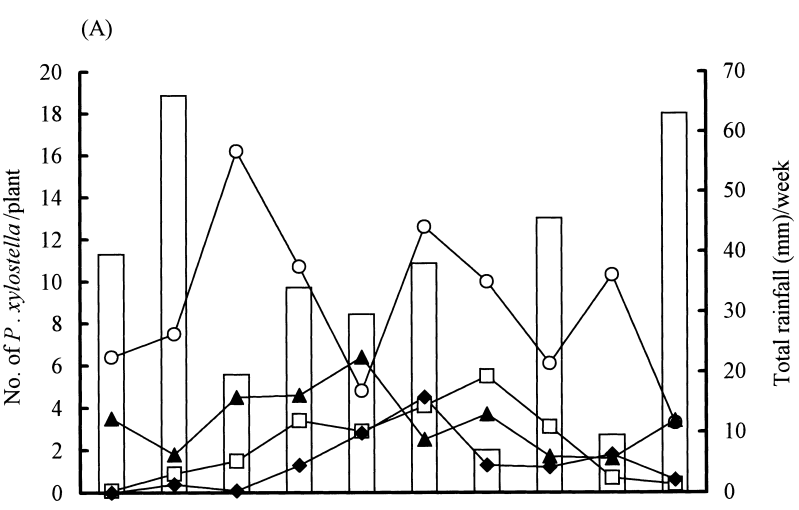

(B)

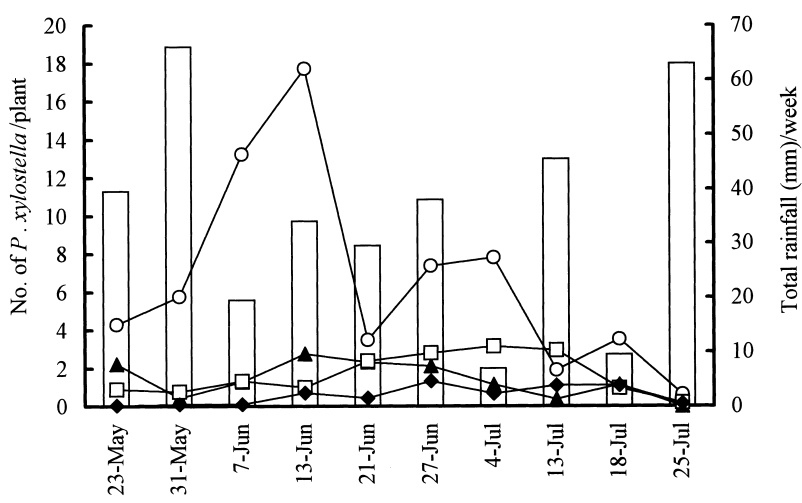

Fig. 1. Population trends of eggs $(O)$, larvae I $(\mathbf{\Delta})$, larvae II ( $\square$ ) and pupae ( $\bullet$ ) of P. xylostella in Kinkei 201 (A) and Shinsei (B) fields. Bars indicate weekly total rainfall at Matsudo during the study period (1998).

period on Shinsei. Weekly total rain trends showed heavy rain during May 24-31 $(66 \mathrm{~mm})$ and July 19-25 (63 mm). Rainfall was moderate during June 22-27 and July 5-13, and low during June 1-7 $(19.5 \mathrm{~mm})$, June 28 to July $4(7 \mathrm{~mm})$ and July $14-18(9.5 \mathrm{~mm})$. The impact of rain on the eggs and larvae $I$ in Shinsei appeared to be more pronounced (Fig. 1A and B).

Population trends of DBM total larvae (larvae I+larvae II), pupae and cocoons of $C$. plutellae in Kinkei 201 field are shown in Fig. 2A. Larval density (no./plant) increased gradually in June and then dropped in July. Pupal density was zero on May 23 and then increased, with a peak on June 27 (4.5 pupae/plant). Maximum numbers of parasitoid cocoons ( 2.3 cocoons/plant) were recorded on June 27. Parasitoid cocoons were first recorded on June 21. At other sampling dates parasitoid density was less than 1.5 cocoons/plant.

The field data for population density of total DBM larvae (larvae I+larvae II), pupae and co- 


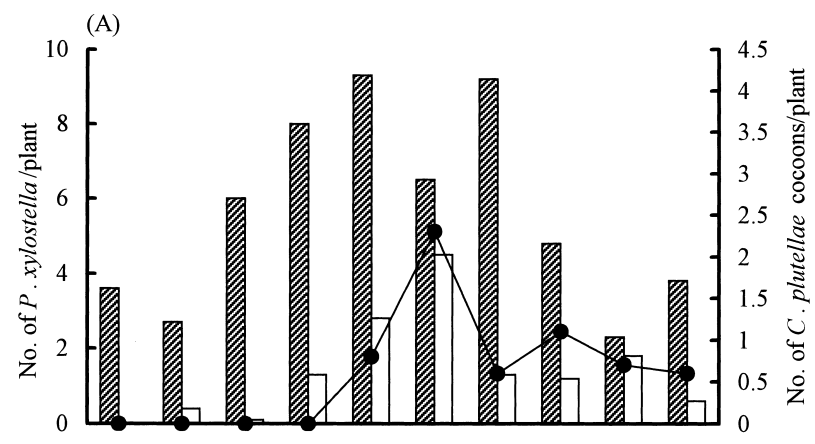

(B)

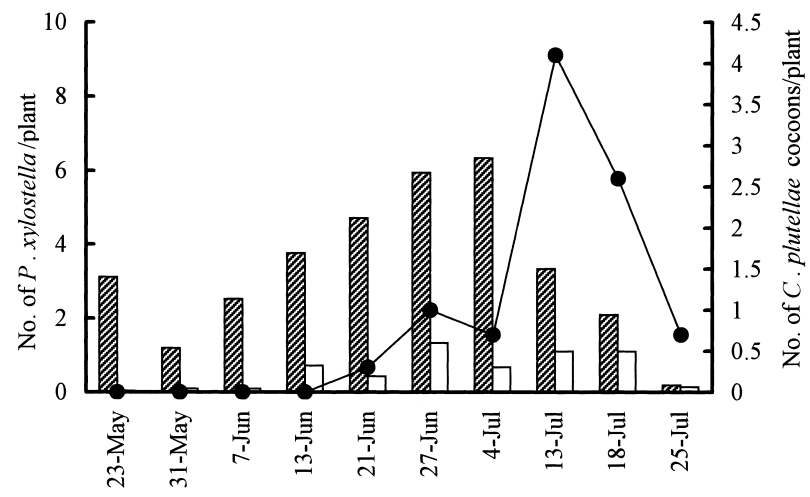

Fig. 2. Population trends of P. xylostella total larvae (ש), pupae ( $\square$ ) and C. plutellae cocoons (๑) in Kinkei 201 (A) and Shinsei (B) fields (1998).

coons of C. plutellae in the Shinsei field are shown in Fig. 2B. Larval density increased steadily until July 4 and then declined sharply. Pupal density stayed at low levels and peaked (1.3 pupae/plant) on June 27. Parasitoid cocoon density peaked on July 13 (4.1 cocoons) and then also declined sharply.

Population density of cocoons of $C$. plutellae on Kinkei 201 and Shinsei showed that the parasitoid appeared in both fields at almost the same period. Regarding its parasitism, certain interesting dissimilarities were observed between Kinkei 201 and Shinsei fields. Overall population trends of parasitoid indicated that the per plant density was comparatively high on Shinsei cabbage, despite the fact that the density of its host (DBM) was higher on Kinkei 201 (Fig. 2A and B).

\section{Parasitoid occurrence}

Two larval (braconid and ichneumonid species), one larval-pupal (eulophid species) and one pupal (ichneumonid species) parasitoids of the DBM and
Table 1. Parasitoid species emerged from immature stages of $P$. xylostella collected from the spring season cabbage at Matsudo in 1998 and 1999

\begin{tabular}{ccc}
\hline S. & Family: Species & Host \\
No. & & (stage)
\end{tabular}

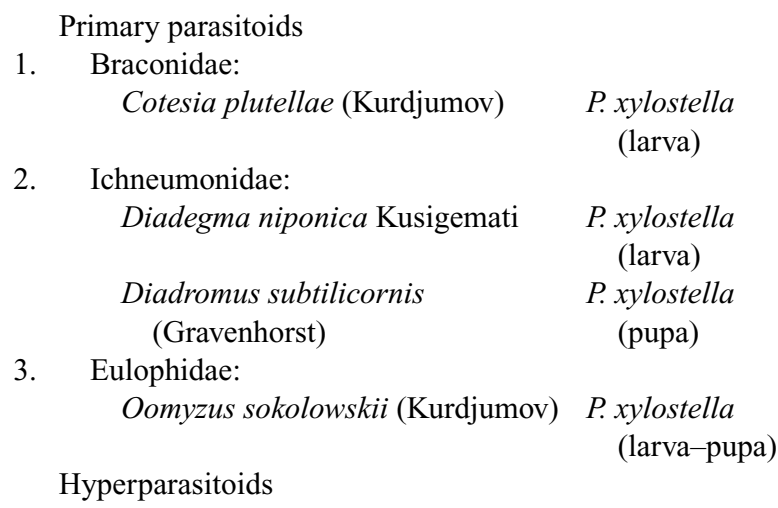

4. Pteromalidae: Trichomalopsis oryzae C. plutellae Kamijo et Grissell

5. Eurytomidae:
Eurytoma sp.
C. plutellae

${ }^{a}$ Parasitoid species were identified by Dr. Kazuhiko Konishi (S. Nos. 1 and 2) and Dr. Kazuaki Kamijo (S. Nos. 3, 4 and $5)$.

two hyperparasitoids (pteromalid and eurytomid species) of $C$. plutellae emerged from host immature stages (Table 1). Among these species, $C$. plutellae, Diadegma niponica Kusigemati, Diadromus subtilicornis (Gravenhorst) and Oomyzus sokolowskii (Kurdjumov) are known as useful parasitoids of the DBM (Okada, 1989; Fitton and Walker, 1992; Noda et al., 1996). Two species, D. subtilicornis and $O$. sokolowskii, were recorded late in the season when crop had already produced heads and temperature was high. We did not find any egg parasitoid of the DBM during the experimental years. Because C. plutellae was observed frequently in most of the samples, we recorded its parasitism. All other parasitoids were recorded in small numbers.

\section{Host parasitism rates of $C$. plutellae on Kinkei 201 and Shinsei}

Our preliminary field results of host parasitism rates of C. plutellae during 1998 determined higher parasitism on Shinsei cabbage compared to Kinkei 201 (Table 2 and Fig. 3). The parasitism continu- 


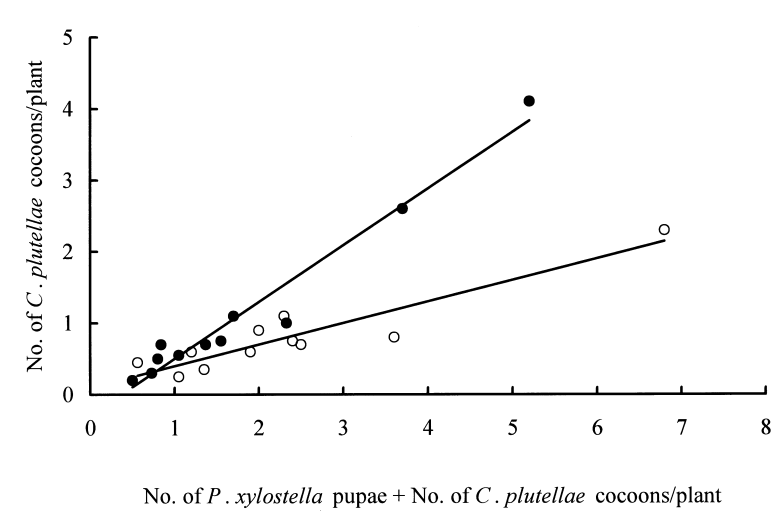

Fig. 3. The relationship of $C$. plutellae cocoons with $P$. xylostella + C. plutellae cocoons per plant on Kinkei $201(\bigcirc)$ and Shinsei (๑) for two consecutive years (1998 and 1999).

Table 2. Parasitism of Plutella xylostella by Cotesia plutellae on Kinkei 201 and Shinsei in field at Matsudo for two spring crop seasons 1998 and 1999

\begin{tabular}{ccc}
\hline & \multicolumn{2}{c}{ \% Parasitism of host by C. plutella ${ }^{\mathrm{a}}$} \\
\cline { 2 - 3 } Sampling date & Kinkei 201 & Shinsei \\
\hline 1998 season & & \\
June 21 & 22.2 & 41.2 \\
June 27 & 33.8 & 43.0 \\
July 4 & 31.6 & 51.1 \\
July 13 & 47.8 & 78.8 \\
July 18 & 28.0 & 70.3 \\
July 25 & 50.0 & 83.3 \\
1999 season & & \\
July 16 & 31.3 & 48.4 \\
July 23 & 23.8 & 52.4 \\
July 30 & 45.0 & 64.7 \\
August 6 & 26.0 & 62.5 \\
August 13 & 18.2 & 40.0 \\
\hline
\end{tabular}

a $\%$ Parasitism $=($ No. of $C$. plutellae cocoons on 20 cabbage plants)/(No. of $C$. plutellae cocoons and of $P$. xylostella pupae on 20 cabbage plants $) \times 100$.

ously increased until the end of the experimental period in spring 1998 and reached 83.4\% (Shinsei) and $50 \%$ (Kinkei 201) on July 25 (Table 2). This trial motivated us to do further study and we repeated the trial during 1999 by growing both varieties. Higher parasitism rates were shown in Kinkei 201 from July 16 to August 13. Parasitism was high at the end of July in Shinsei (64.7\%) and Kinkei 201 (45\%) fields. The results of 1999 also indicated higher parasitism rates of $C$. plutellae on Shinsei cabbage (Table 2 and Fig. 3). The regression lines of Kinkei $201(Y=0.30 x+0.09, r=0.92)$ and Shinsei $(Y=0.79 x-0.28, r=0.97)$ further confirmed the significant difference $(p<0.05)$ in parasitoid numbers between the two varieties based on host and parasitoid densities per plant.

\section{DISCUSSION}

Cabbage is one of the main economical crucifer vegetables in Japan. Diamondback moth larvae cause huge economical losses every year unless effective chemicals are sprayed. Reducing cabbage damage by keeping the DBM below threshold levels through pesticide use became difficult because of resistance problems (Cheng, 1988; Magaro and Edelson, 1990; Tabashnik et al., 1990). In our limited study we investigated the population trends of the DBM, host of C. plutellae. In addition, potential impacts of $C$. plutellae on these varieties were observed. Our results are valuable and unique, as we did not use any pesticides while studying the population trends of pest and parasitoid in the cabbage fields. Moreover, certain important parasitoids of the DBM were reared and identified.

Larval density of DBM on Kinkei 201 showed increasing trends (3.6-4.8 larvae/plant) starting from May 23 to July 13. On the same variety, parasitism by $C$. plutellae was recorded on June 21 , however parasitoid density was low. At these levels farmers usually apply certain control measures especially pesticides to save cabbage. In contrast larval pest loads in Shinsei may indicate the need for crop protection measures starting June 7 to July 4 when larval density of 2.5-6.3 larvae per plant was observed. On Shinsei, parasitism by $C$. plutellae was also recorded on June 21. However, it was apparently higher on Shinsei when compared with Kinkei 201 during the two seasons. Several plant traits can influence the ability of natural enemies to suppress the populations of herbivorous insects (Price, 1986; Barbosa and Letourneau, 1988). However, in the case of $C$. plutellae, we do not yet know the exact characteristics of Shinsei cabbage plants that influenced the parasitoid, regardless of the fact that parasitism by $C$. plutellae may have some role in suppressing the larval population.

Developed DBM-resistant cabbage cultivars include those with glossy leaves and genotypes with normal waxy bloom. Resistant glossy varieties are only effective against 1st stadium larvae, suggesting that the mechanism of resistance in glossy 
genotypes is the rejection of plants by 1st instars, which results in higher net movement and less feeding. This behavioral difference may lead to increased larval mortality on glossy plants due to starvation and desiccation (Eigenbrode et al., 1990; Eigenbrode and Shelton, 1990). Despite extensive research on the host plant resistance of Brassica oleracea var. capitata (common cabbage) to the DBM, knowledge of the resistance mechanisms involved remains incomplete (Verkerk and Wright, 1994, 1996). However, we believe that the impact of rain on the DBM immatures of these two varieties may differ as a result of both physiological and morphological dissimilarities between them. The combined effects of these factors may produce a lower pest load in Shinsei cabbage.

In another study (Talekar and Yang, 1991), $C$. plutellae parasitism was higher when the DBM larvae were fed on Chinese cabbage (75\%) than on common cabbage $(55 \%)$, cauliflower $(60 \%)$ or broccoli $(37.50 \%)$. However, the exact mechanism causing the differences in parasitism rates is still obscure. Our study showed higher parasitism rates by parasitoids on Shinsei cabbage even at lower larval host densities when compared with Kinkei 201.

Annamalai et al. (1988) reported 38\% mortality of the DBM from the direct impact of rain which washed off the eggs. They further found that loss of eggs from the upper leaf surface of cabbage was greater $(>50 \%)$ than from the lower surface. However, in the present study, we did not directly quantify this effect on the immature stages of the DBM. Rain may also influence the mating and egg laying behaviors of adults. Wakisaka et al. (1991) revealed in a study that, excluded rainfall on some cabbage plots with a plastic roof, that one third to one half of the DBM disappeared in the early immature stages. Since the mortality rate was lower in the plots with no rainfall, they speculated that removal of the eggs and larvae by rain and drowning of young larvae after rain was the major mortality factor. The effectiveness of integrated methods to control the DBM was investigated in Hawaii, and the results showed that the pest was effectively and economically controlled through the implementation of an intermittent overhead sprinkler system operating between 08:00 and 22:00 h and weekly releases of the braconid C. plutellae (Nakahara et al., 1986). They also suggested that intermittent ap- plication of water in the field during the early hours could disrupt the mating and oviposition activities of the DBM.

An inventory of parasitoid species emerged from the DBM shows that the parasitoid complex against the DBM around the Matsudo area is poorly developed. We were successful in recovering only four parasitoid species and two hyperparasitoids during our two year study. Augmentations of these primary parasitoids may play a useful role in controlling the DBM. In the present study, $C$. plutellae was considered as a major parasitoid found on both varieties. However, we assume that this parasitoid species alone may not contribute much to DBM control because of high population levels of the pest. Therefore, not only augmentation but also conservation of these beneficials is necessary for sustainable biological control. Recently in Miyazaki Pref., Japan, seven parasitoid species were reported from the larvae and pupae of the DBM. Among them the percentage parasitism by $C$. plutellae, $O$. sokolowskii and $D$. subtilicornis was recorded at about $70 \%, 50$ to $60 \%$ and $>40 \%$, respectively (Uematsu and Yamashita, 1999). Natural enemies could play a vital role in IPM of cabbage pest(s). Yet these are underutilized in IPM programs developed for ephemeral crops in urban environments, such as cabbage, because quantitative information on the role of natural enemies in biological control is lacking and/or information on the effects of natural enemies on pest populations are unavailable to pest managers.

Concluding our preliminary results we suggest that further studies on the potential role of parasitoids, selective pesticides and resistant cultivars are urgently needed to devise an effective cabbage pest management around this production area.

\section{ACKNOWLEDGEMENTS}

We are grateful to Dr. Kazuhiko Konishi (formerly National Institute of Agro-Environmental Sciences) and Dr. Kazuaki Kamijo (Bibai, Hokkaido) for identification of wasp species. We wish to express our sincere thanks to the officials of Matsudo City Hall for providing the meteorological data. Special thanks are extended to Dr. Masashi Nomura and Dr. Shingo Toyoshima (Chiba University) for their kind help. The first author wishes to express his deep gratitude to the Ministry of Education, Science, Sports and Culture of Japan (Monbusho) for the postgraduate merit scholarship grant. This work was supported in part by a Grant-in-Aid for Scientific Research No. (A) (1) 09306003 of the Ministry of Education, Science, Sports and Culture of Japan. The invaluable help of two 
anonymous-reviewers for the improvement of this publication is highly acknowledged.

\section{REFERENCES}

Adachi, T. and K. Futai (1992) Changes in insecticide susceptibility of the diamondback moth in Hyogo, Japan. JARQ 26: 144-151.

Annamalai, S., Y. Ito and T. Saito (1988) Population fluctuations of the diamondback moth Plutella xylostella (L.) on cabbages in Bacillus thuringiensis sprayed and unsprayed plots and factors affecting within generation survival of immatures. Res. Popul. Ecol. 30: 329-342.

Back, C. E. and B. E. Tabashnik (1990) Effects of non-host plant neighbors on population densities and parasitism rates of the diamondback moth (Lepidoptera: Plutellidae). Environ. Entomol. 19: 987-994.

Barbosa, P. and D. K. Letourneau (1988) Novel Aspects of Insect-Plant Interactions. Wiley, New York. 362 pp.

Cheng, E. Y. (1988) Problem of control of insect resistant Plutella xylostella. Pestic. Sci. 23: 177-188.

Eigenbrode, S. D. and A. M. Shelton (1990) Behaviour of neonate diamondback moth larvae (Lepidoptera: Plutellidae) on glossy-leafed resistant Brassica oleracea L. Environ. Entomol. 19: 1566-1571.

Eigenbrode, S. D., A. M. Shelton and M. H. Dickson (1990) Two types of resistance to the diamondback moth (Lepidoptera: Plutellidae) in cabbage. Environ. Entomol. 19: 1086-1090.

Fitton, M. and A. Walker (1992) Hymenopterous parasitoids associated with diamondback moth: the taxonomic dilemma. In Proceedings of the Second International Workshop on Diamondback Moth and Other Cruciferous Pests (N. S. Talekar ed.). AVRDC, Tainan, Taiwan, pp. 225-232.

Hama, H. (1990) Insecticide resistance of diamondback moth, Plutella xylostella in Japan. JARQ 24: 22-30.

Haseeb, M. and H. Amano (2001) Effects of contact, oral and persistent toxicity of selected pesticides on Cotesia plutellae (Hym., Braconidae), a potential parasitoid of Plutella xylostella (Lepidoptera: Plutellidae). Z. Angew. Entomol. (in press).

Haseeb, M., H. Amano and H. Nemoto (2000a) Pesticidal effects on mortality and parasitism rates of Diadegma semiclausum, a parasitoid of the diamondback moth. BioControl 45: 165-178.

Haseeb, M., H. Amano and H. Nemoto (2000b) Effects of pesticides on the mortality and beneficial capacity of $\mathrm{Di}$ adegma semiclausum (Hymenoptera: Ichneumonidae), a primary parasitoid of the diamondback moth. IOBC/ WPRS Bull. 23: 39-48.

Hirashima, Y., M. Abe and O. Tadauchi (1989) The hymenopterous parasitoids of the diamondback moth, Plutella xylostella (Lepidoptera: Yponomeutidae) in Japan. Esakia 28: 63-73.

Idris, A. B. and E. Grafius (1996) Effects of wild and cultivated host plants on oviposition, survival, and development of diamondback moth (Lepidoptera: Plutellidae) and its parasitoid Diadegma insulare (Hymenoptera: Ichneumonidae). Environ. Entomol. 25: 825-833.
Iga, M. (1985) The seasonal prevalence of occurrence and the life tables of the diamondback moth, Plutella xylostella (L.) (Lepidoptera: Yponomeutidae). Jpn. J. Appl. Entomol. Zool. 29: 119-125 (in Japanese with English summary).

Lim, G. S. (1986) Biological control of the diamondback moth. In Proceedings of the First International Workshop on Diamondback Moth Management (N. S. Talekar and T. D. Griggs eds.). AVRDC, Tainan, Taiwan, pp. 159-171.

Magaro, J. J. and J. V. Edelson (1990) Diamondback moth (Lepidoptera: Plutellidae) insecticide resistance in south Texas. A technique for resistance monitoring in the field. J. Econ. Entomol. 83: 1201-1206.

Mitchell, E. R., G. Y. Hu, J. S. Okine and J. E. Carpenter (1999) Parasitism of diamondback moth (Lepidoptera: Plutellidae) larvae by Cotesia plutellae (Hymenoptera: Braconidae) and Diadegma insulare (Hymenoptera: Ichneumonidae) in cabbage fields after inundative releases of C. plutellae. J. Entomol. Sci. 34: 101-112.

Muckenfuss, A. E. and B. M. Shepard (1994) Seasonal abundance of diamondback moth, Plutella xylostella (L.) (Lepidoptera: Plutellidae) and natural enemies to esfenvalerate and Bacillus thuringiensis subsp. kurstaki Berliner in coastal South Carolina. J. Agric. Entomol. 11: 361-373.

Nakahara, L. M., J. J. McHugh Jr., C. K. Otsuka, G. Y. Funasaki and P. Y. Lai (1986) Integrated control of diamondback moth and other insect pests using an overhead sprinkler system, an insecticide and biological control agents on a watercress farm in Hawaii. In Proceedings of the First International Workshop on Diamondback Moth Management (N. S. Talekar and T. D. Griggs eds.). AVRDC, Tainan, Taiwan, pp. 403-413.

Nemoto, H. (1993) Mechanism of resurgence of the diamondback moth, Plutella xylostella (L.) (Lepidoptera: Yponomeutidae). JARQ 27: 27-32.

Nemoto, H., E. Yano and K. Kiritani (1992) Pheromonal control of diamondback moth in the management of crucifers pests. In Proceedings of the Second International Workshop on Diamondback Moth and Other Cruciferous Pests (N. S. Talekar ed.). AVRDC, Tainan, Taiwan, pp. 91-97.

Noda, T., S. Miyai, S. Yamada and K. Konishi (1996) Larval and pupal parasitoids of diamondback moth Plutella $x y$ lostella (L.) in cabbage fields in Morioka, Japan. Jpn. J. Appl. Entomol. Zool. 40: 164-167 (in Japanese with English summary).

Okada, T. (1989) Parasitoids of the diamondback moth Plutella xylostella (L.) (Lepidoptera: Yponomeutidae): species and seasonal changes of parasitism in cabbage fields. Jpn. J. Appl. Entomol. Zool. 33: 17-23 (in Japanese with English summary).

Price, P. W. (1986) Ecological aspects of host plant resistance and biological control: interactions among three trophic levels. In Interactions of Plant Resistance and Parasitoids and Predators of Insects (D. J. Boethel and R. D. Eikenbarry eds.). Wiley, New York, pp. 11-30.

Sheehan, W. (1986) Response by specialist and generalist natural enemies to agroecosystem diversification: a selective review. Environ. Entomol. 15: 456-461. 
StatView (1998) StatView (ver. 5.0) for windows. SAS Institute Inc., Cary, NC 27513.

Tabashnik, B. E., N. L. Cushing, N. Finson and M. W. Johnson (1990) Field development of resistance to Bacillus thuringiensis in diamondback moth (Lepidoptera: Plutellidae). J. Econ. Entomol. 83: 1671-1679.

Talekar, N. S. and A. M. Shelton (1993) Biology, ecology and management of the diamondback moth. Annu. Rev. Entomol. 38: 275-301.

Talekar, N. S. and J. C. Yang (1990) Use of parasitoids for controlling the diamondback moth, Plutella xylostella (Lepidoptera: Yponomeutidae). International Seminar on the Use of Parasitoids and Predators to Control Agricultural Pests (October 2-7, 1989), Tsukuba Science City, Ibaraki-ken 305, Japan. 21 pp.

Talekar, N. S. and J. C. Yang (1991) Characteristics of parasitism of diamondback moth by two larval parasites. Entomophaga 36: 95-104.

Talekar, N. S. and J. C. Yang (1993) Influence of crucifer cropping system on the parasitism of Plutella xylostella (Lepidoptera: Yponomeutidae) by Cotesia plutellae (Hymenoptera: Braconidae) and Diadegma semiclausum (Hymenoptera: Ichneumonidae). Entomophaga 38: 541550 .

Uematsu, H. and T. Yamashita (1999) Seasonal occurrence of diamondback moth, Plutella xylostella (L.) in some com- mercial cruciferous fields in Miyazaki, southern Japan. Jpn. J. Appl. Entomol. Zool. 43: 113-121 (in Japanese with English summary).

Verkerk, R. H. J. and D. J. Wright (1994) Interactions between the diamondback moth, Plutella xylostella L. and glasshouse and outdoor-grown cabbage cultivars. Ann. Appl. Biol. 125: 477-488.

Verkerk, R. H. J. and D. J. Wright (1996) Common cabbage resistance mechanisms against the diamondback moth: Still an open book? Ann. Appl. Biol. 128: 571-577.

Wakisaka, S., R. Tsukuda and F. Nakasuji (1991) Life tables of the diamondback moth, Plutella xylostella (L.) (Lepidoptera: Yponomeutidae) and effects of rainfall, temperature, and host plants on survival and reproduction. Jpn. J. Appl. Entomol. Zool. 35: 115-122 (in Japanese with English summary).

Yamamura, K. (1999) Relation between plant density and arthropod density in cabbage fields. Res. Popul. Ecol. 41: $177-182$

Yamamura, K. and E. Yano (1999) Effects of plant density on the survival rate of cabbage pests. Res. Popul. Ecol. 41: 183-188.

Yaseen, M. (1978) The establishment of two parasites of the diamondback moth Plutella xylostella (Lep.: Plutellidae) in Trinidad, W. I. Entomophaga 23: 111-114. 